\title{
Explorations in Bibliography
}

\section{Zotero Goes Public}

Gregory Morrison, Wheaton College

\begin{abstract}
The publishing of scholarly bibliographies has diminished significantly over the past two decades for an obvious reason: access to bibliographic tools via the Internet. But this has not marked the end altogether of research-level bibliographies, which are still vital to the preservation and advancement of knowledge. Research bibliographies are finding a new home online, and open source tools are now available to help scholars and librarians reestablish this genre in dynamic fashion. This listen and learn session discussed one such project that deploys Zotero, Tablesorter, and Libguides to serve a targeted group of users.
\end{abstract}

The core components of my session are Zotero, LibGuides, BibBase, and Tablesorter. Zotero has emerged as the "darling" reference management program. I will assume that everyone present is familiar already with Springshare's LibGuide program. It serves as the public interface for presenting the bibliographies that I will introduce in a minute. BibBase (https://bibbase.org) takes advantage of Zotero's API to enable researchers to "set up and maintain a scientific publications page," while Tablesorter (https://mottie.github. io/tablesorter/docs/) is described as "a jQuery plug-in [that] can successfully parse and sort many types of data including linked data in a cell." Tablesorter and BibBase offer alternative solutions for publishing bibliographies to the web. BibBase is very simple to use and requires no coding or programming knowledge. Tablesorter, in contrast, exists as open-source code that one can "fork" from GitHub and customize, which is what we did at Wheaton and named it "BibTable." We offer the code for BibTable to anyone here who wants to use it. 
Before I launch into the details of how these tools work and work together, allow me a brief historical excursus. If you imagined that the number of printed bibliographies has declined since the 1990s when the Internet took off, you would be correct. According to a search in WorldCat, the heyday for bibliographies was between 1960 and 1980, when approximately 115,000 bibliographies were published. Since 2000, the number of printed bibliographies dropped to around 19,000. The decline was predictable, of course, as researchers could rely increasingly on resources like WorldCat, Google Scholar, and article databases to quickly generate customized, up-to-date lists of references. Many of the published bibliographies from the mid-twentieth century (I can confirm this from a recent weeding project) were little more than lists of references, but others provided an introduction to that area of scholarship and included annotations to some or all of the titles. I found some of these works worth keeping for their value to the study of academic disciplines and publishing and their potential usefulness to subject bibliographers.

The bibliography as a genre has found some life in the digital space. Oxford Bibliographies Online (OBO) seems to be the most significant effort to date. Also, though not easy to identify, researchlevel bibliographies are available on the Internet. One example is a web site devoted to the study of the early church figure, Evagrius Ponticus, available at http://evagriusponticus.net/index.htm. This is an actively curated research guide that is maintained by Joel Kalvesmaki at Dumbarton Oaks and has an advisory board made up of scholars at other institutions including Harvard and Catholic University of America and on that basis considers itself a "peerreviewed publication."

With the exception of being peer-reviewed, the Evagrius guide represents the model I have followed for my research guide on the integration of faith and learning in evangelical higher education. In its original conception, the guide aimed to be a "prolegomenon" for the study of Christian faith and learning. That goal proved to be too ambitious, and I revised the guide several years later to target a more specific user group, namely, newer Wheaton faculty who, if on a tenure track, are required to write a "faith and learning paper" within the first five or six years in order to receive tenure and promotion to the associate professor rank. The second target group 
remained administrators at other Christian colleges-especially such schools abroad-who are interested in establishing a faculty faith and learning program similar to Wheaton's. A review of hits on the site revealed, in fact, an international interest in the content of the guide. My suggestion to you is to consider likewise what unique research interests your institution may have around which you can develop this kind of resource.

As for the execution of such a research bibliography, Zotero functions as the database. You simply create a folder for whatever bibliography you want to build and publish. At the BibBase web site, you are invited to "Get your BibBase Page" and Zotero is one of several source options. Clicking on the Zotero link, you will be prompted to log into the web version of Zotero. Each collection (i.e., folder) appears with another link. Once you click on the specific collection, the bibliography is generated along with three options for embedding it in a web page including Javascript, PHP, and iFrame. Javascript is the "easiest." The code is provided for you to cut and paste into the page; I work in LibGuides as my web editor but one can use whatever platform is available that supports basic world wide web protocols. Zotero-BibBase-Libguides is the easiest package for starters. View a sample page at https://wheaton.libguides.com/ onlinebibs_atla2019. I chose to replace BibBase with TableSorter because of some functionality issues with BibBase in the LibGuides environment but it did require involving a library colleague with greater expertise in coding. As I mentioned earlier, this colleague modified the code from GitHub and this code is available upon request. Send the request to research.help@wheaton.edu.

I want to end by saying more about the content of the public bibliographies on the faith and learning research guide at http:// wheaton.libguides.com/faithandlearning. I worked to identify the journals and magazines that publish "integrative" works. Christian Scholar's Review and Zygon: Journal of Religion and Science are prime examples. Some but not all of the integrative periodicals I selected are indexed in one or more databases. Others are not indexed anywhere. So, I committed to building (in a Zotero collection) an index to the selected journals, which represents the most timeconsuming part of maintaining the guide and keeping it up-to-date. I must confess that I'm not doing so well to keep this commitment. 
Going forward, I need to develop a maintenance schedule and get in the habit of conducting searches to update the Zotero folders that feed these public bibliographies. Otherwise, more frequent users will begin to notice and not return. 